\title{
Longer duration of obesity is associated with a reduction in urinary angiotensinogen in prepubertal children
}

\author{
Manuela Morato ${ }^{1,2,3,4}$ (D) Liane Correia-Costa ${ }^{5,6,7} \cdot$ Teresa Sousa $^{1,3} \cdot$ Dina Cosme $^{1,5}$. \\ Franz Schaefer $^{8}$ • José Carlos Areias ${ }^{9}$ - António Guerra ${ }^{7,10,11}$. \\ Alberto Caldas Afonso ${ }^{5,6,7}$ • Henrique Barros ${ }^{5,12}$ • Ana Azevedo ${ }^{5,12}$. \\ António Albino-Teixeira ${ }^{1,3}$
}

Received: 29 July 2016 / Revised: 27 February 2017 / Accepted: 27 February 2017 /Published online: 23 March 2017

(C) IPNA 2017

\begin{abstract}
Background We aimed to study the impact of obesity on urinary excretion of angiotensinogen (U-AGT) in prepubertal children, focusing on the duration of obesity and gender. Also, we aimed to evaluate whether plasma angiotensinogen (P-AGT) and hydrogen peroxide $\left(\mathrm{H}_{2} \mathrm{O}_{2}\right)$ play a role in the putative association.

Methods Cross-sectional evaluation of 305 children aged 89 years (160 normal weight, 86 overweight, and 59 obese). Anthropometric measurements and 24-h ambulatory blood pressure monitoring were performed. Angiotensinogen (AGT) was determined by a commercial enzyme-linked im-
\end{abstract}

Manuela Morato and Liane Correia-Costa contributed equally as first authors to this paper.

Ana Azevedo and António Albino-Teixeira contributed equally to the supervision and scientific revision of this paper.

Manuela Morato

mmorato@ff.up.pt

1 Department of Pharmacology and Therapeutics, Faculty of Medicine of University of Porto, Porto, Portugal

2 Department of Drug Sciences, Laboratory of Pharmacology, Faculty of Pharmacy of the University of Porto, Rua Jorge Viterbo Ferreira, 228, 4050-313 Porto, Portugal

3 MedInUP - Center for Drug Discovery and Innovative Medicines, University of Porto, Porto, Portugal

4 Laboratory of Pharmacology, Department of Drug Sciences, Faculty of Pharmacy of University of Porto, Porto, Portugal

5 EPIUnit - Institute of Public Health, University of Porto, Porto, Portugal

6 Division of Pediatric Nephrology, Integrated Pediatric Hospital, Centro Hospitalar São João, Porto, Portugal munosorbent assay (ELISA) kit and $\mathrm{H}_{2} \mathrm{O}_{2}$ by a microplate fluorometric assay.

Results U-AGT and P-AGT levels were similar across body mass index (BMI) groups and between sexes. However, boys who were overweight/obese since the age of 4 years presented lower levels of U-AGT compared with those of normal weight at the same age. In children who were overweight/obese since the age of 4 , urinary $\mathrm{H}_{2} \mathrm{O}_{2}$ decreased with P-AGT.

Conclusions A higher duration of obesity was associated with decreased U-AGT in boys, thus reflecting decreased intrarenal activity of the renin-angiotensin system. Also, children with a

7 Department of Pediatrics, Faculty of Medicine of University of Porto, Porto, Portugal

8 Division of Pediatric Nephrology, Center for Pediatrics and Adolescent Medicine, University of Heidelberg,

Heidelberg, Germany

9 Division of Pediatric Cardiology, Integrated Pediatric Hospital, Centro Hospitalar São João, Porto, Portugal

10 Division of Pediatric Nutrition, Integrated Pediatric Hospital, Centro Hospitalar São João, Porto, Portugal

11 CINTESIS - Center for Research in Health Technologies and Information Systems, Faculty of Medicine, University of Porto, Porto, Portugal

12 Department of Clinical Epidemiology, Predictive Medicine and Public Health, Faculty of Medicine of University of Porto, Porto, Portugal 
longer duration of obesity showed an inverse association between urinary $\mathrm{H}_{2} \mathrm{O}_{2}$ and P-AGT. Future studies should address whether these results reflect an early compensatory mechanism to limit obesity-triggered renal dysfunction.

Keywords Angiotensinogen · Obesity · Overweight · Body mass index $\cdot$ Children $\cdot$ Hydrogen peroxide

\section{Introduction}

The prevalence of childhood obesity has tripled in the last three decades, reaching epidemic proportions around the world [1]. Even at younger ages, obesity triggers a cascade of metabolic changes that contribute to the development of hypertension, diabetes, atherosclerosis, and chronic renal disease $[2,3]$. Besides, obesity in childhood and adolescence predicts the risk of cardiovascular morbidity and premature mortality in adults [4]. The mechanisms underlying the association between a high body mass index (BMI) in childhood and adolescence and cardiovascular and kidney disease in adulthood are not well characterized, and no biomarkers are available for use in routine clinical practice to allow early identification of high-risk children.

The renin-angiotensin-aldosterone system (RAAS) has been implicated in the harmful consequences of obesity. This well-coordinated hormonal system regulates cardiovascular and renal function by controlling fluid and electrolyte homeostasis. Furthermore, tissue RAAS exists in specific tissues, namely the kidney and adipose tissue [5]. In the adipose tissue, RAAS components are highly expressed and secreted by mature adipocytes [6-8], although contradictory findings have been reported regarding its regulation in obese conditions. Some studies report an increased expression [6] and secretion [5, 9] of adipose tissue-derived RAAS components in obese individuals that might contribute to activate systemic RAAS and potentiate its deleterious effects $[6,8,10,11]$. Other studies describe reduced expression of angiotensinogen (AGT) in adipose tissue that parallels the time course of adipocyte hypertrophy, which is tightly associated with the progression of obesity [12].

Childhood obesity is also associated with renal injury, and the kidney is particularly vulnerable to the effects of the RAAS, both through the hemodynamic impact of systemic RAAS activation and by local intrarenal activation, mostly derived from AGT produced in the proximal tubule [7, 13]. Urinary excretion of AGT (U-AGT) has been validated as a noninvasive biomarker of intrarenal RAAS activity [13] and increased U-AGT has been found in human hypertension, diabetes, and renal disease [13] even in adolescents [14, 15] and children [16]. The rise in U-AGT precedes the onset of microalbuminuria, suggesting that U-AGT might be an early marker of nephropathy [15]. Interestingly, excessive activation of the adipose RAAS seems to be crucial for establishment and progression of kidney disease [13, 17] but only two small sample studies have been performed in the setting of human obesity $[7,18]$. In both studies, no difference was found in U-AGT between obese adults and nonobese controls. Remarkably, it was recently highlighted that not only severity but also duration of obesity can determine obesity-related target-organ lesions $[19,20]$ but neither of those studies took that in consideration. Also, the study of Thethi et al. showed that obese women had higher U-AGT than obese men, although there was no gender difference in the nonobese group [7]. Gender is known to influence blood pressure (BP) and cardiovascular and renal functions, and evidence implies that the RAAS might be a putative link in this association [21]. These data raise the possibility of gender differences in the association between RAAS and obesity.

The deleterious effects of intrarenal RAAS are due, at least in part, to potentiation of angiotensin II (Ang II)-mediated renal effects $[2,7]$, namely the production of reactive oxygen species and cytokines and the stimulation of cell growth, inflammation and fibrosis [13, 22]. Hydrogen peroxide $\left(\mathrm{H}_{2} \mathrm{O}_{2}\right)$, a nonradical oxidant and a known mediator of Ang II effects [23], also appears to be involved in the regulation of RAAS components. Recent experimental studies suggest that $\mathrm{H}_{2} \mathrm{O}_{2}$ increases AGT expression in the kidney but induces its downregulation in adipose tissue [12, 24-26]. However, this relationship between $\mathrm{H}_{2} \mathrm{O}_{2}$ and AGT has not yet been explored in humans.

We aimed at characterizing the impact of obesity on UAGT in prepubertal, otherwise healthy, children. We compared U-AGT between normal weight, overweight, and obese children and evaluated whether gender or obesity duration influence the putative association between obesity and UAGT at this age. Furthermore, since experimental evidence indicates $\mathrm{H}_{2} \mathrm{O}_{2}$ as a modulator of AGT expression both in kidney and adipose tissue [12, 24-26], we evaluated the link between urinary excretion of $\mathrm{H}_{2} \mathrm{O}_{2}\left(\mathrm{U}-\mathrm{H}_{2} \mathrm{O}_{2}\right)$, U-AGT, and plasma AGT (P-AGT) levels.

\section{Methods}

\section{Study design and sample collection}

We conducted a cross-sectional study of children aged 89 years followed since birth in a previously established Portuguese cohort study (Generation XXI) [27]. Children from the original cohort ( $n=8647$ newborns) were eligible for the ObiKid project if they had anthropometric data and a blood sample withdrawn at the study site in the 7-year-old evaluation (Fig. 1; $n=4590$ ). For the Obikid project [28], we wanted to include a minimum sample of 300 children, since this sample size would provide a statistical power of 


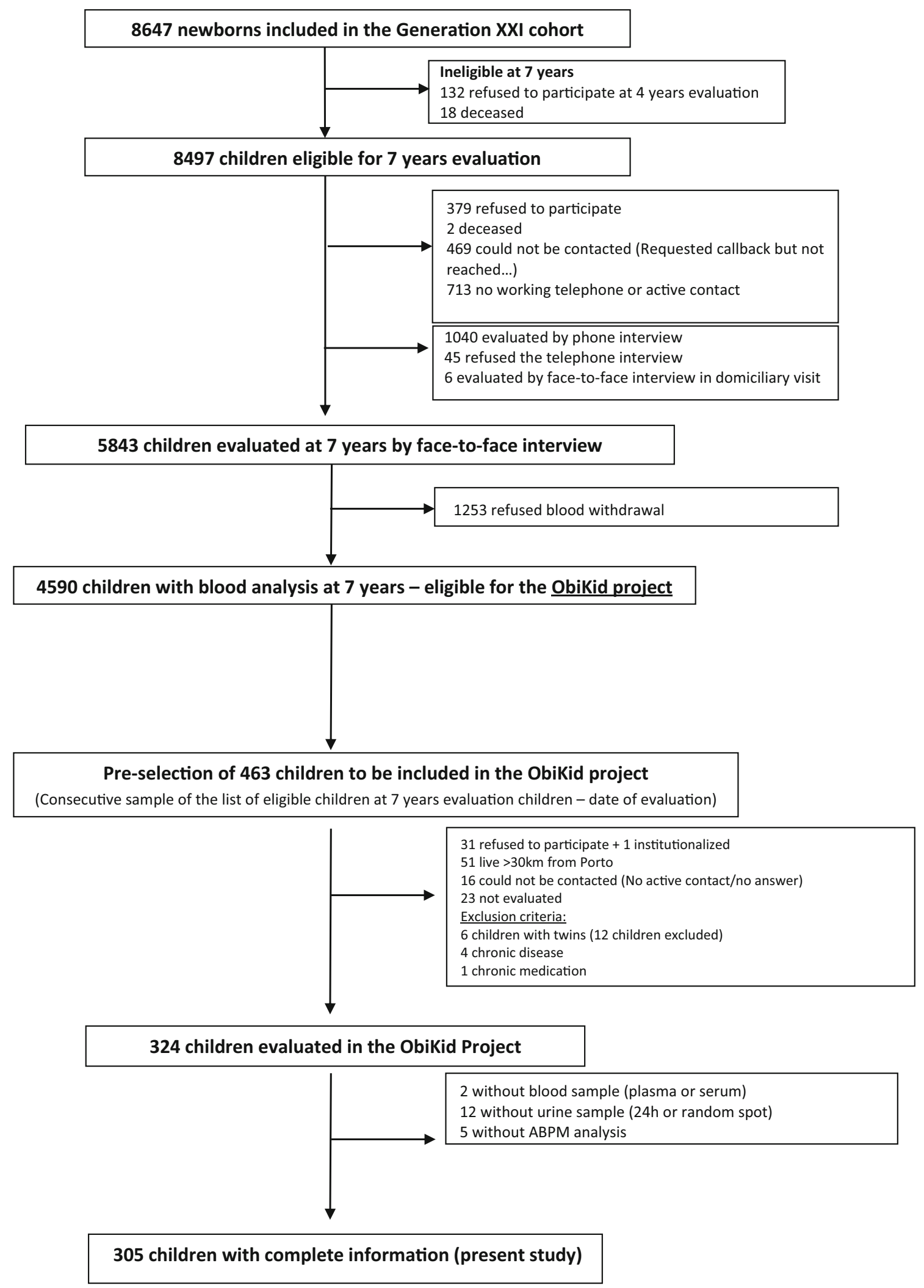

Fig. 1 Patient inclusion

$85 \%$ with a significance level of 0.05 to detect a difference in estimated glomerular filtration rate (eGFR) of at least $8 \mathrm{ml} /$ $\min / 1.73 \mathrm{~m}^{2}$ between normal weight and overweight/obese children, assuming a standard deviation (SD) of 24 and 
$22 \mathrm{ml} / \mathrm{min} / 1.73 \mathrm{~m}^{2}$ in each group, respectively [29]. We assumed that a minimum of $35 \%$ of children would be excluded due to refusal to participate, exclusion criteria, or incomplete information. We needed to consecutively screen and attempt to contact 463 children from the 4590 eligible ones to obtain the required sample; 16 could not be contacted, 32 refused to participate, 23 were unable to schedule study visits during the recruitment period, and 68 met exclusion criteria [four chronic diseases (genetic, renal, or metabolic), one chronic usage of medication (affecting BP, glucose, or lipid metabolism), 51 living far from the study site, and 12 twins]. Participants with acute illness, namely febrile conditions, were asked to postpone the scheduled study visit for a period of at least 15 days after total recovery. We finally enrolled 324 participants, but for our analysis 19 were excluded due to absence of adequate blood or urine samples or missing values in variables of interest. Our study therefore assessed 305 children (Fig. 1). No significant differences were found between included and eligible children with respect to sex, weight, height, systolic/ diastolic BP, and parental education level at the follow-up visit at 7 years of age.

\section{Data collection and variable definition}

The study visits took place at the Department of Clinical Epidemiology, Predictive Medicine and Public Health, Faculty of Medicine, University of Porto. Data on birth and neonatal characteristics were abstracted from clinical records. Gestational age was considered as determined by ultrasonography. Classes of the sex-specific adequate birth weight for gestational age were defined according to the populationbased Canadian reference curves $(<10$ th percentile $=$ small for gestational age; $\geq 10$ th percentile and $<90$ th percentile $=$ adequate for gestational age; $\geq 90$ th percentile $=$ large for gestational age) [30]. Anthropometric and general physical examinations assessed weight, height, waist circumference and body composition by bioelectrical impedance analysis (percent body fat mass). Data collection was performed according to standard procedures and as previously reported [31]. Waist circumference was indexed to height [waist-to-height ratio (WHtR) in $\mathrm{cm} / \mathrm{m}$ ] for statistical analysis. BMI-for-age values were classified according to the World Health Organization (WHO) growth reference data for BMI z-score into the following categories: normal weight $(-2 \mathrm{SD}$ to $+1 \mathrm{SD})$; overweight $(>+1 \mathrm{SD})$, and obesity $(>+2 \mathrm{SD})$ [32]. To evaluate the effect of duration of obesity on variables studied, we gathered the most recent anthropometric data available from the previous evaluations of the cohort; accordingly, data at 4 years of age was gathered and analyzed. At that age, BMI-for-age values were classified according to the WHO growth reference data for BMI $z$-score for children $<5$ years [33]. Among overweight/obese children at the age of 8-9 with anthropometric evaluation at the age of $4(n=132)$, two groups were considered: those known to be overweight or obese since the age of 4 ( $n=88 ; 39$ girls, 49 boys) and those classified as normal weight at the age of 4 ( $n=44 ; 18$ girls, 26 boys).

Ambulatory BP monitoring (ABPM) was performed for $24 \mathrm{~h}$ with a portable, noninvasive, oscillometric BP recorder (Spacelabs Healthcare®, model 90207). The nondominant arm was used to allow free movement during everyday activity and reduce measurement errors due to movement artifacts. Cuff size was chosen according to patient's arm circumference. BP measurements were taken automatically at 20-min intervals during the day and at 30-min intervals during the night. A minimum monitoring duration of $24 \mathrm{~h}$ with gaps $<2 \mathrm{~h}$ was required for acceptance; five of the ABPM analysis examinations were excluded due to insufficient readings. Readings were used to calculate mean $24 \mathrm{~h}$, daytime and nighttime mean arterial (MAP), systolic (SBP) and diastolic (DBP) pressures, using SpaceLabs ${ }^{\circledR}$ software. SD scores for $B P$ values were calculated (least mean square method) according to the published reference values of the German Working Group on Pediatric Hypertension [34]. To characterize circadian BP rhythmicity, we calculated the percentage of nocturnal fall in MAP using the following formula: [mean daytime $\mathrm{MAP}-$ mean nighttime MAP]/[mean daytime MAP] $\times 100$. The nondipping pattern was considered when a drop in nighttime MAP $<10 \%$ of the corresponding daytime BP was observed.

\section{Laboratory procedures}

A venous blood sample was collected from all participants after an overnight fast of at least $8 \mathrm{~h}$ and analyzed for cystatin $\mathrm{C}$, creatinine, uric acid, aldosterone, and P-AGT. All participants collected a spot urine sample, which was analyzed for albumin, creatinine, and U-AGT, and a 24-h urine sample, which was analyzed for $\mathrm{H}_{2} \mathrm{O}_{2}$. All standard laboratory measurements were performed in the Clinical Pathology Department of Centro Hospitalar São João, Porto, Portugal. Serum cystatin $\mathrm{C}$ was assayed using a particle-enhanced immunonephelometric assay ( $\mathrm{N}$ latex Cystatin $\mathrm{C}$, Siemens $\left.{ }^{\circledR}\right)$. Serum creatinine assay was based on the Jaffé compensated traceable to an isotope dilution mass spectrometry method (Olympus AU 5400 automated analyzer, Beckman-Coulter®, USA). Urinary creatinine and albumin were determined with the same clinical immunochemistry analyzer. GFR was estimated by the Zappitelli combined formula (in $\mathrm{ml} / \mathrm{min} / 1.73 \mathrm{~m}^{2}$ ) [35]. Aldosterone concentration was measured using Liaison Aldosterone Kit ${ }^{\circledR}$ (DiaSorin Inc., USA) in serum samples. Urinary and plasma concentrations of AGT and urinary excretion of $\mathrm{H}_{2} \mathrm{O}_{2}$ were assessed in the Department of Pharmacology and Therapeutics of the Faculty of Medicine at the University of Porto. AGT was quantified by an immunoenzymatic method, using a commercial enzymelinked immunosorbent assay (ELISA) kit (Human Total 
Angiotensinogen Assay Kit, Immuno-Biological Laboratories Co., Gunma, Japan) and $\mathrm{H}_{2} \mathrm{O}_{2}$ evaluated using a microplate fluorometric assay (Amplex Red Hydrogen Peroxide/ Peroxidase Assay Kit, Molecular Probes, Alfagene, Carcavelos, Portugal), according to protocols provided by the manufacturers. Data concerning AGT and $\mathrm{H}_{2} \mathrm{O}_{2}$ have been recently used by our group as part of studies on the same cohort to evaluate the association with urinary fibrogenic cytokines [36] and oxidative stress [37], respectively.

\section{Statistical analysis}

Data are presented as mean and SD or, if skewed, as median and 25th-75th percentiles (P25-P75). U-AGT, P-AGT, and $\mathrm{U}-\mathrm{H}_{2} \mathrm{O}_{2}$ had an asymmetric distribution and were logarithmized (base 10) before linear regression analyzes, allowing a normal distribution to be obtained. The tertiles of WHtR, percent of body fat mass, and U-AGT were defined based on all enrolled participants. Linear trend was tested using linear regression models with BMI z-score classes and tertiles of WHtR and body fat mass included as independent continuous variables and U-AGT (logarithm base 10) as the dependent variable. Tertiles of P-AGT were used as independent variables and $\mathrm{H}_{2} \mathrm{O}_{2}$ (logarithm base 10) as the dependent variable. Models were additionally adjusted for sex and age (in months).

\section{Results}

A total of 305 children (54\% male) with a mean (SD) age of $8.8(0.2)$ years were assessed. General characteristics and levels of biochemical parameters are shown in Tables 1 and 2 , respectively, by BMI classes (160 normal weight, 86 overweight, and 59 obese children). Overweight and obese children had higher birth weight but no differences in distribution in classes of adequacy of birth weight for gestational age. Overweight and obese children presented significantly higher values of 24-h and nighttime MAP values (Table 1). Regarding analytical parameters, overweight and obese children presented higher uric acid, creatinine, and cystatin $\mathrm{C}$ levels and lower eGFR values. No differences were found in median values of aldosterone, U-albumin, or $\mathrm{U}-\mathrm{H}_{2} \mathrm{O}_{2}$ across groups (Table 2).

The levels of U-AGT were not significantly different across BMI classes (normal weight 5.6 (3.7-7.6); overweight $5.3(3.4-8.3)$; obese $4.8(2.8-7.8) \mu \mathrm{g} / \mathrm{g}$ of creatinine, $p=$ 0.338 ) and neither were P-AGT levels (normal weight 36.6 (32.4-47.3); overweight 37.3 (32.6-44.8); obese 38.8 (34.144.3) $\mu \mathrm{g} / \mathrm{ml}, p=0.780$ ) (Table 2). The distribution of U-AGT and P-AGT levels by classes of BMI and tertiles of WHtR and body fat mass is shown in Fig. 2. Regardless of the obesity index considered, no significant differences were found in the linear trend analysis of U-AGT or P-AGT levels (Fig. 2).

No differences were found between sexes in median PAGT [38.5 (33.6-46.2) vs. 36.3 (31.7-43.4) $\mu \mathrm{g} / \mathrm{ml}, p=$ 0.069 , in girls and boys, respectively] or U-AGT [5.1 (2.8$8.5)$ vs. $5.5(3.7-7.3) \mu \mathrm{g} / \mathrm{g}$ of creatinine, $p=0.370$, in girls and boys, respectively] levels. However, in the overweight/obese group, those known to be overweight or obese since the age of 4 were more likely to excrete less U-AGT compared with those classified as normal weight at the age of 4 , with this difference being significant only in boys (Table 3 ). This is indicated by the fact that in boys (but not in girls) who were overweight/obese at the age of 8-9 years only, a markedly higher percent of cases was found in the 2 nd and 3 rd tertiles of U-AGT, while in boys overweight/obese since the age of 4, the distribution of cases is relatively homogeneous across the three U-AGT tertiles (Table 3).

Linear trend analysis showed that the levels of $\mathrm{U}-\mathrm{H}_{2} \mathrm{O}_{2}$ decreased across P-AGT tertiles in the overweight/obese group [1st tertile: 1577.0 (959.1-2008.9), 2nd tertile: 1328.9 (701.7-2380.1), 3rd tertile: 846.5 (466.0-1609.4) nmol/day, $p$ for trend $=0.039]$ but not in the normal-weight group [1st tertile: 1007.5 (666.9-2030.7), 2nd tertile: 1323.4 (861.82133.4), 3rd tertile: 1522.2 (704.2-2055.3) nmol/day, $p$ for trend $=0.548)$ ] Moreover, among overweight/obese children, the effect of $\mathrm{U}-\mathrm{H}_{2} \mathrm{O}_{2}$ on P-AGT levels was significant in those classified as overweight/obese since the age of 4 , but not in those who were not (Fig. 3). The levels of $\mathrm{U}-\mathrm{H}_{2} \mathrm{O}_{2}$ were similar across U-AGT tertiles in children who were overweight/ obese at the age of 8-9; in those who were overweight/obese since the age of 4 , there was a marginally significant ( $p=$ 0.053; Fig. 3) decrease of $\mathrm{U}-\mathrm{H}_{2} \mathrm{O}_{2}$ values across U-AGT tertiles.

\section{Discussion}

Previous studies have shown an increase in U-AGT in children with renal disease of different etiologies [16, 38, 39], namely in adolescents with type 1 diabetes [15] or with primary hypertension [14], and in children with very low birth weight [40]. Based on these published data and on the negative impact that obesity has on the kidney [2], we would expect that overweight/obese children had higher U-AGT than age-matched controls of normal weight. However, as recently reported by our group [36], we observed no significant differences in U-AGT between normal and overweight/obese children. In this study, we further extended this result and clarified that it is observed regardless of the obesity index considered: classes of BMI or tertiles of WHtR or percent body fat mass. Although contrary to our initial hypothesis this result in obese but otherwise healthy children is in accordance with that of the only two studies concerning obesity and intrarenal RAAS, 
Table 1 General characteristics of study participants by BMI zscore classes

\begin{tabular}{|c|c|c|c|c|}
\hline & \multicolumn{3}{|c|}{ BMI z-score classification } & \multirow[t]{2}{*}{$P$ value } \\
\hline & Normal weight $n=160$ & $\begin{array}{l}\text { Overweight } n= \\
86\end{array}$ & Obese $n=59$ & \\
\hline \multicolumn{5}{|c|}{ General characteristics and anthropometry } \\
\hline Age (months) & $105.1 \pm 3.0$ & $105.2 \pm 2.8$ & $105.5 \pm 2.8$ & 0.663 \\
\hline Male sex & $83(52 \%)$ & $43(50 \%)$ & $40(68 \%)$ & 0.069 \\
\hline Gestational age (weeks) & $38.8 \pm 1.9$ & $38.9 \pm 1.3$ & $38.9 \pm 1.2$ & 0.891 \\
\hline Birth weight (g) & $3185 \pm 483$ & $3266 \pm 383$ & $3354 \pm 442$ & 0.040 \\
\hline Birth weight for gestational age ${ }^{a}$ & & & & 0.923 \\
\hline Small (<10th percentile) & $22(13.8 \%)$ & $11(12.8 \%)$ & $6(10.2 \%)$ & \\
\hline $\begin{array}{l}\text { Adequate (10th-90th } \\
\text { percentile) }\end{array}$ & $133(83.1 \%)$ & $72(83.7 \%)$ & $50(84.7 \%)$ & \\
\hline Large ( $\geq 90$ th percentile) & $5(3.1 \%)$ & $3(3.5 \%)$ & $3(5.1 \%)$ & \\
\hline BMI $\left(\mathrm{kg} / \mathrm{m}^{2}\right)$ & $16.0 \pm 1.2$ & $19.5 \pm 0.9$ & $23.3 \pm 2.4$ & $<0.001$ \\
\hline Z-score & $-0.04 \pm 0.74$ & $1.56 \pm 0.30$ & $2.66 \pm 0.49$ & $<0.001$ \\
\hline WHtR $(\mathrm{cm} / \mathrm{m})$ & $44.7 \pm 2.6$ & $50.2 \pm 3.2$ & $56.6 \pm 4.4$ & $<0.001$ \\
\hline Percent body fat mass & $10.6 \pm 7.1$ & $20.0 \pm 8.0$ & $27.7 \pm 9.4$ & $<0.001$ \\
\hline \multicolumn{5}{|l|}{ 24-h ambulatory BP } \\
\hline 24-h MAP (mmHg) & $81.1 \pm 4.4$ & $82.5 \pm 5.2$ & $82.9 \pm 6.3$ & 0.030 \\
\hline Z-score & $0.35 \pm 0.90$ & $0.69 \pm 1.07$ & $0.51 \pm 0.92$ & 0.032 \\
\hline Daytime MAP (mmHg) & $84.8 \pm 4.6$ & $85.8 \pm 5.8$ & $86.2 \pm 6.5$ & 0.157 \\
\hline Z-score & $0.06 \pm 0.86$ & $0.28 \pm 0.96$ & $0.15 \pm 0.96$ & 0.219 \\
\hline Nighttime MAP (mmHg) & $73.4 \pm 4.9$ & $74.8 \pm 5.2$ & $75.6 \pm 6.3$ & 0.011 \\
\hline Z-score & $0.52 \pm 0.91$ & $0.85 \pm 0.94$ & $0.72 \pm 0.79$ & 0.022 \\
\hline MAP dipping (\%) & $13.4 \pm 4.7$ & $12.6 \pm 5.2$ & $12.3 \pm 4.5$ & 0.212 \\
\hline Nondipping pattern & $34(22 \%)$ & $30(35 \%)$ & $17(29 \%)$ & 0.082 \\
\hline
\end{tabular}

Mean \pm standard deviation or $n(\%)$. BMI z-score classification is according to WHO criteria (normal weight, overweight, and obesity) [32]

$B M I$ body mass index, WHtR waist-to-height ratio, MAP mean arterial pressure

${ }^{a}$ According to the population-based Canadian reference curves [30]

which reported similar U-AGT between obese and nonobese adults $[7,18]$. In contrast, animal models of obesity show an imbalance of renal RAAS components. Obese animals have increased expression of angiotensin-converting enzyme (ACE) and of $\mathrm{AT}_{1}$ and $\mathrm{AT}_{2}$ receptors, but decreased expression of ACE2 and Mas receptor [41]. Adipose-derived AGT determines P-AGT concentration that, by controlling circulating AngII levels, stimulates proximal tubule production of AGT [11], thus activating intrarenal RAAS activity. Although plasma levels of AGT are increased in obese hypertensive compared with nonobese hypertensive patients [42], in our population, P-AGT was similar between normal and overweight/obese children, whatever obesity index was considered. The fact that we found similar levels of U-AGT and PAGT might be associated with the duration of obesity (i.e., that might be not enough to have a negative impact on kidney function), activation of slow operating compensatory mechanisms, or both. Interestingly, it has been reported that obesity severity, duration, and age at onset might be crucial for the development and progression of obesity-related organ damage. Using a contemporary population from the Framingham study, Abdullah et al. suggested that a construct of obese-years should be preferable to BMI or duration of obesity alone to estimate the obesity-associated risk of type 2 diabetes [20]. Also, an adolescent onset of obesity was found to have a stronger impact on diabetes risk than adultonset obesity [19]. When we analyzed our group of overweight/obese children according to the duration of overweight/obesity, we observed those with a longer duration presented lower levels of U-AGT than those with recent offset of overweight/obesity. This was quite unexpected given that if renal RAAS progressively contributes to renal damage, along with the duration of excessive weight, then children already overweight/obese by the age of 4 would show higher U-AGT. Some children in our population were identified as being obese at the age of 4 but as being of normal weight at the age of 8-9; however, this group was too small to be analyzed.

Interestingly, we previously reported [28] an already lower eGFR in these overweight/obese children, although renal function was in the normal range for all children. Also, we 
Table 2 Laboratory data by BMI z-score classes

\begin{tabular}{|c|c|c|c|c|}
\hline & \multicolumn{3}{|c|}{ BMI z-score classification } & \multirow{2}{*}{$\begin{array}{l}P \\
\text { values }\end{array}$} \\
\hline & $\begin{array}{l}\text { Normal weight } \\
n=160\end{array}$ & Overweight $n=86$ & Obese $n=59$ & \\
\hline \multicolumn{5}{|l|}{ Blood analytical parameters } \\
\hline Uric acid (mg/dl) & $3.5 \pm 0.7$ & $3.8 \pm 0.7$ & $4.0 \pm 0.8$ & $<0.001$ \\
\hline Creatinine (mg/dl) & $0.43 \pm 0.06$ & $0.45 \pm 0.06$ & $0.45 \pm 0.06$ & 0.003 \\
\hline Cystatin-C (mg/L) & $0.64 \pm 0.07$ & $0.67 \pm 0.08$ & $0.68 \pm 0.06$ & $<0.001$ \\
\hline eGFR $\left(\mathrm{ml} / \mathrm{min} / 1.73 \mathrm{~m}^{2}\right)$ & $138.4 \pm 15.8$ & $132.2 \pm 16.4$ & $132.1 \pm 13.2$ & 0.003 \\
\hline Aldosterone (ng/dl) & $9.4(7.1-13.2)$ & $12.1(7.5-16.2)$ & $9.6(8.4-13.8)$ & 0.216 \\
\hline P-AGT $(\mu \mathrm{g} / \mathrm{ml})^{\mathrm{a}}$ & $36.6(32.4-47.3)$ & $37.3(32.6-44.8)$ & $38.8(34.1-44.3)$ & 0.780 \\
\hline \multicolumn{5}{|c|}{ Urinary analytical parameters } \\
\hline $\begin{array}{l}\text { U-albumin }(\mathrm{mg} / \mathrm{g} \\
\text { creatinine })\end{array}$ & $4.1(2.6-7.6)$ & $3.6(2.1-7.8)$ & $3.7(2.3-5.6)$ & 0.560 \\
\hline $\begin{array}{l}\text { U-AGT }(\mu \mathrm{g} / \mathrm{g} \\
\text { creatinine }^{\mathrm{a}}\end{array}$ & $5.6(3.7-7.6)$ & $5.3(3.4-8.3)$ & $4.8(2.8-7.8)$ & 0.338 \\
\hline $\mathrm{U}-\mathrm{H}_{2} \mathrm{O}_{2}(\mathrm{nmol} / \text { day })^{\mathrm{b}}$ & $\begin{array}{l}1282.0 \\
\quad(711.1-2058.7)\end{array}$ & $\begin{array}{l}1328.9 \\
\quad(680.5-1988.5)\end{array}$ & $\begin{array}{l}1276.2 \\
\quad(701.7-2187.2)\end{array}$ & 0.855 \\
\hline
\end{tabular}

Mean \pm standard deviation or median (P25-P75). BMI z-score classification is according to WHO criteria (normal weight, overweight, and obesity) [32]

$B M I$ body mass index, $e G F R$ estimated glomerular filtration rate by Zappitelli combined formula, $P-A G T$ plasma angiotensinogen, $U$-albumin urinary albumin-to-creatinine ratio, $U$-AGT urinary angiotensinogen, $U-H_{2} \mathrm{O}_{2}$ urinary hydrogen peroxide

Data concerning AGT $\left({ }^{\mathrm{a}}\right)$ and $\mathrm{H}_{2} \mathrm{O}_{2}\left({ }^{\mathrm{b}}\right)$ have been recently used by our group as part of studies on the same cohort intended to evaluate the association with urinary fibrogenic cytokines [36] and oxidative stress [37], respectively recently reported [36] that urinary excretion of the fibrogenic cytokines endothelin-1 (ET-1) and transforming growth factor- $\beta 1$ (TGF- $\beta 1$ ) was not increased in obese children in our cohort; indeed, they showed lower levels of urinary ET1 and TGF- $\beta 1$ than those of normal weight. Furthermore, UAGT was associated with urinary excretion of ET-1 and TGF- $\beta 1$ [23]. Of note, although there are reports of human studies showing increased expression of AGT messenger RNA (mRNA) in subcutaneous adipose tissue of obese individuals [43], most human and animal studies report a decrease $[9,12,44]$. Moreover, expression and secretion of AGT decreases as adipocytes become hypertrophied. This effect seems to be, at least in part, mediated by reactive oxygen species, namely, $\mathrm{H}_{2} \mathrm{O}_{2}$ [12]. Consistent with this, we observed an inverse association between $\mathrm{P}-\mathrm{AGT}$ and $\mathrm{U}-\mathrm{H}_{2} \mathrm{O}_{2}$ in overweight/obese children but not in normal-weight controls. Moreover, that association was seen only in children overweight/obese by the age of 4 . So, although further studies are needed to fully evaluate and characterize this point, our results suggest that childhood obesity is associated with timedependent alterations in intrarenal RAAS activity (even when established markers of renal function are in the normal range) and with an association between P-AGT and $\mathrm{U}-\mathrm{H}_{2} \mathrm{O}_{2}$.

It is noteworthy that the difference observed in U-AGT according to duration of obesity was only significant in boys. In girls, the levels of U-AGT were not associated with the duration of overweight/obesity . Studies in animal models suggest that the kidney has estrogen receptors that can mediate protective effects against renal injury by attenuating glomerulosclerosis and tubulointerstitial fibrosis $[45,46]$. Interestingly, this protection has been suggested to involve both the RAAS and the endothelin system [45]. The children in our study are at a prepubertal age and we were not able to quantify neither Tanner stages nor sex hormones. As such, although we recruited a homogeneous population, we cannot conclude whether prepubertal girls already have higher levels of estrogens and androgen metabolites than prepubertal boys, as reported elsewhere [47, 48]. Moreover, the fact that obesity might anticipate puberty in girls and delay it in boys [49] could somehow blunt the impact of obesity on U-AGT levels. In other words, the absence of difference in U-AGT according to duration of obesity in girls could also be explained by the fact that girls in the obese group were at a more advanced phase of pubertal development. In line with this, we also observed that boys excreted significantly more $\mathrm{H}_{2} \mathrm{O}_{2}$ than girls (unpublished observations) and that in boys, higher salt consumption was associated with higher systolic BP, specifically in those overweight/obese [50].

Major strengths of our study are inclusion of a large and homogeneous sample of healthy prepubertal children and the gathering of data on 24-h ABPM and renal function from all of them. The cross-sectional design of our study might be seen as a limitation. However, as our cohort will be followed until adulthood, we expect to re-evaluate these children in the next evaluation period, when they will be adolescents, and it will 

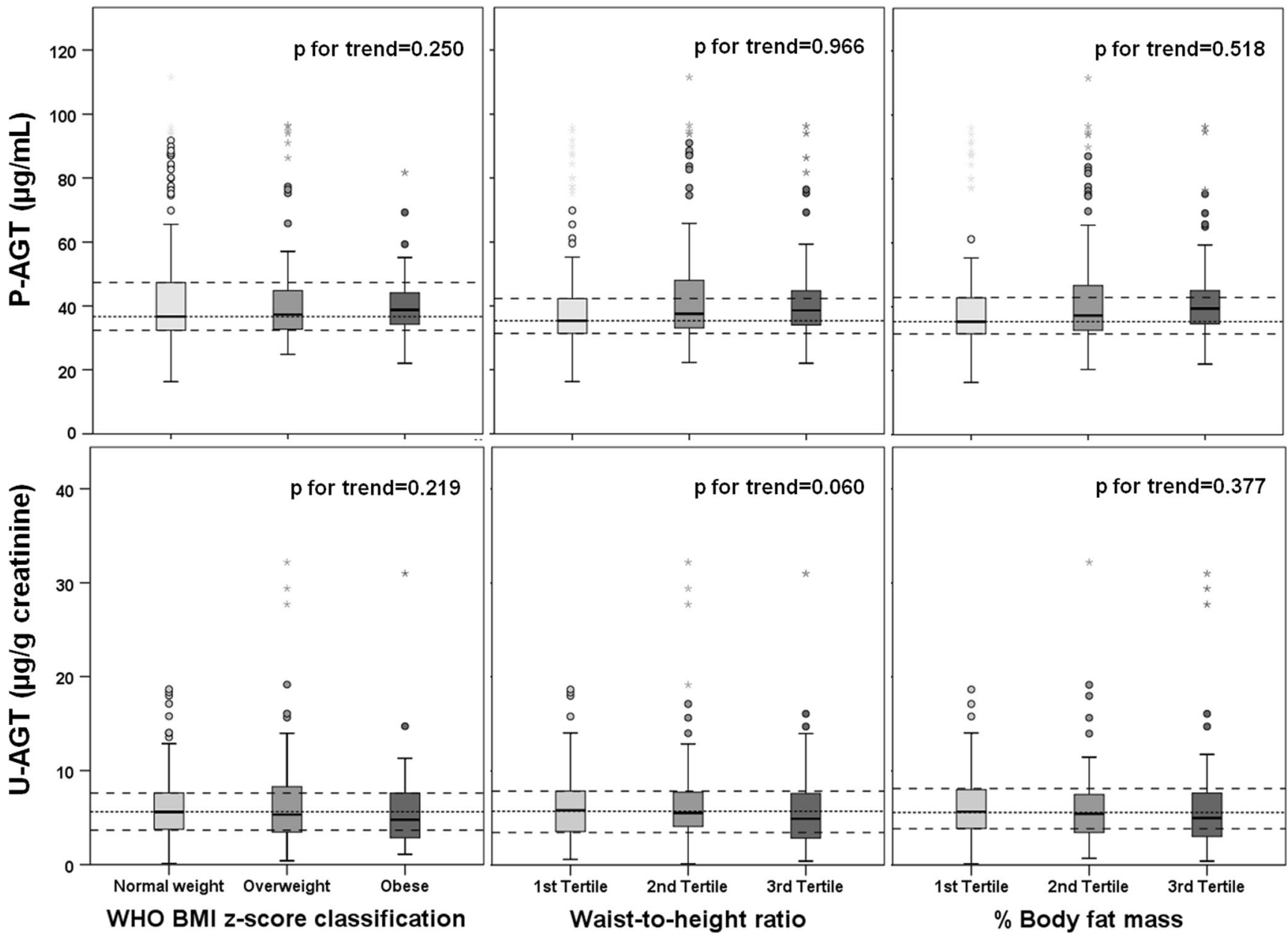

Fig. 2 Distribution of P-AGT and U-AGT by classes of BMI and tertiles of waist-to-height ratio and percent body fat mass. Normal weight, overweight, and obesity group classification is according to the WHO classification for BMI z-score [32]. Tertiles of waist-to-height ratio $(\leq 45.65$; $45.66-50.00 ;>50.00)$ and percent of body fat mass $(\leq 11.10 ; 11.11-$ $20.70 ;>20.70)$ were divided based on all enrolled participants. P-AGT and U-AGT data is expressed as medians and percentiles 25 and 75. $P$

values for linear trend across groups were calculated by linear regression using U-AGT as dependent variable (logarithm base 10) and adjusting for sex and age in months. Horizontal dashed lines represent the 25th, 50th, and 75th percentiles in the normal-weight group for each parameter. $W H O$ World Health Organization, $B M I$ body mass index, $P$-AGT plasma angiotensinogen, $U$-AGT urinary angiotensinogen

be possible to perform a longitudinal analysis to complement and expand the hypothesis raised in this study. In addition, longitudinal studies should include a group of children that has experienced weight loss to test whether that would protect them from metabolic changes later in life.
Our results reinforce the importance of encouraging preventive measures targeting obesity even in prepubertal children, since obesity seems to have an impact on kidney function even at this young age. Moreover, data on sex hormones and Tanner stages would have enriched our analysis significantly.
Table 3 Distribution of cases (\%) across urinary excretion of angiotensinogen (U-AGT) tertiles

\begin{tabular}{|c|c|c|c|}
\hline & \multicolumn{3}{|c|}{ U-AGT ( $\mu \mathrm{g} / \mathrm{g}$ creatinine) } \\
\hline & 1st tertile & 2nd tertile & 3rd tertile \\
\hline \multicolumn{4}{|l|}{ Boys $(p=0.036)$} \\
\hline Overweight/obese since the age of 4 & $36.7 \%$ & $34.7 \%$ & $28.6 \%$ \\
\hline Overweight/obese only at the age of 8-9 & $11.5 \%$ & $61.5 \%$ & $26.9 \%$ \\
\hline \multicolumn{4}{|l|}{ Girls $(p=0.383)$} \\
\hline Overweight/obese since the age of 4 & $48.7 \%$ & $12.8 \%$ & $38.5 \%$ \\
\hline Overweight/obese only at the age of 8-9 & $38.9 \%$ & $27.8 \%$ & $33.3 \%$ \\
\hline
\end{tabular}


Fig. 3 Distribution of $\mathrm{U}-\mathrm{H}_{2} \mathrm{O}_{2}$ by tertiles of P-AGT and U-AGT, according to duration of overweight/obesity. Tertiles of PAGT $(\leq 35.0 ; 35.0-41.5 ;>41.5)$ and U-AGT $(\leq 4.1 ; 4.1-6.7 ;>6.7)$ were divided based on all enrolled participants. $\mathrm{U}-\mathrm{H}_{2} \mathrm{O}_{2}$ data is expressed as medians and percentiles 25 and 75. $P$ values for linear trend across groups were calculated by linear regression using $\mathrm{U}-\mathrm{H}_{2} \mathrm{O}_{2}$ as dependent variable (logarithm base 10) and adjusting for sex and age in months. WHO World Health Organization, $B M I$ body mass index, $\mathrm{U}-\mathrm{H}_{2} \mathrm{O}_{2}$ urinary hydrogen peroxide, $P$-AGT plasma angiotensinogen, $U-A G T$ urinary angiotensinogen
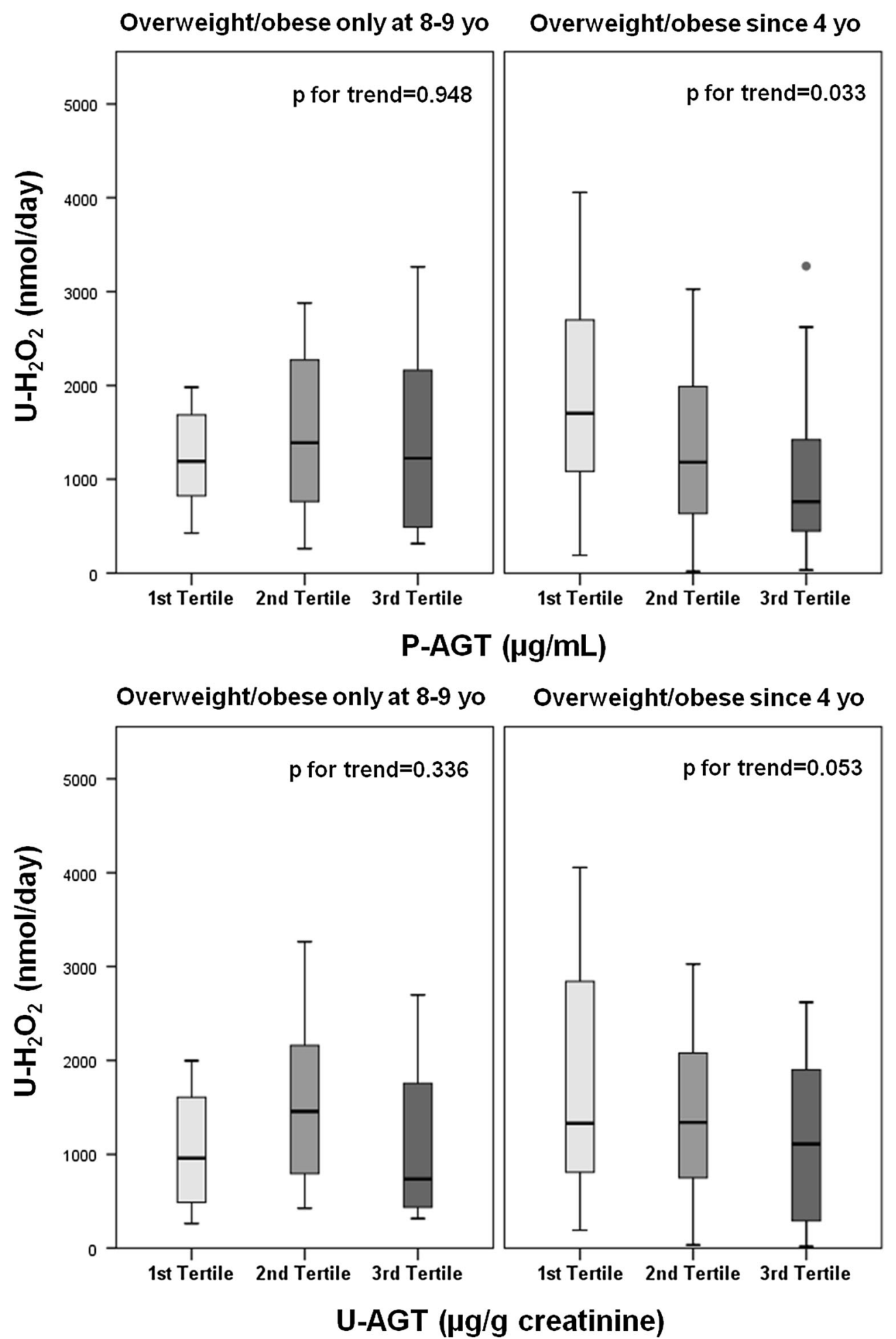

Alternatively, studies in prepubertal children should be conducted at even youger ages so that the differences in hormonal levels would not bias the interpretation of the associated results. Certainly, future analysis by our group will pursue this issue.

In conclusion, although intrarenal RAAS activity in overweight and obese children was similar to that of a normal- weight control group, overweight/obese boys - but not girlswith a longer duration of obesity presented lower levels of UAGT and an inverse association between $\mathrm{U}-\mathrm{H}_{2} \mathrm{O}_{2}$ and P-AGT. This might tempt one to think that ACE inhibitors or angiotensin receptor bolckers (ARBs) could be less effective in protecting the kidney of obese patients. However, this study is 
the first to address the role of the RAAS in the context of obesity-induced renal damage. Also, it focused on short-lasting, early childhood obesity, which might not have the same consequences as chronic obesity. Therefore, further studies are essential (including longitudinal studies) to support evidenced-based guidelines for obese patients, since this population has only been addressed in expert opinion and not in actual guidelines.

Acknowledgements The authors gratefully acknowledge the families enrolled in Generation XXI for their kindness, all members of the research team for their enthusiasm and perseverance and the participating hospitals and their staff for their help and support.

Compliance with ethical standards The Generation XXI study was approved by the Ethics Committee of Centro Hospitalar São João, E.P.E. and Faculty of Medicine of the University of Porto, Portugal, and by the National Data Protection Commission. It complies with the Helsinki Declaration and the current national legislation. Written informed consent from parents (or their legal substitute) and verbal assent from children was obtained, concerning information and biological samples gathering.

Conflicts of interest None of the authors have any financial or nonfinancial competing interests concerning the present study.

Sources of funding This project was supported by funds from Fundo Europeu de Desenvolvimento Regional (FEDER) from Programa Operacional Factores de Competitividade - COMPETE (FCOMP-010124-FEDER-028751), by national funds from the Portuguese Foundation for Science and Technology (FCT) (PTDC/DTP-PIC/0239/ 2012) and by Calouste Gulbenkian Foundation, that granted the study design and data collection and analysis. Liane Correia-Costa was supported by FCT (grant SFRH/SINTD/95898/2013), Teresa Sousa was supported by FCT and POPH/FSE (EC) (Ciência 2008 and SFRH/BPD/112005) and Franz Schaefer was supported by the ERA-EDTA Research Programme and the KfH Foundation for Preventive Medicine. The Epidemiology Research Unit (EPIUnit) is funded by FCT (UID/DTP/ 04750/2013).

\section{References}

1. Ng M, Fleming T, Robinson M, Thomson B, Graetz N, Margono C, Mullany EC, Biryukov S, Abbafati C, Abera SF, Abraham JP, AbuRmeileh NME, Achoki T, AlBuhairan FS, Alemu ZA, Alfonso R, Ali MK, Ali R, Guzman NA, Ammar W, Anwari P, Banerjee A, Barquera S, Basu S, Bennett DA, Bhutta Z, Blore J, Cabral N, Nonato IC, Chang JC, Chowdhury R, Courville KJ, Criqui MH, Cundiff DK, Dabhadkar KC, Dandona L, Davis A, Dayama A, Dharmaratne SD, Ding EL, Durrani AM, Esteghamati A, Farzadfar F, Fay DF, Feigin VL, Flaxman A, Forouzanfar MH, Goto A, Green MA, Gupta R, Hafezi-Nejad N, Hankey GJ, Harewood HC, Havmoeller R, Hay S, Hernandez L, Husseini A, Idrisov BT, Ikeda N, Islami F, Jahangir E, Jassal SK, Jee SH, Jeffreys M, Jonas JB, Kabagambe EK, Khalifa SE, Kengne AP, Khader YS, Khang YH, Kim D, Kimokoti RW, Kinge JM, Kokubo Y, Kosen S, Kwan G, Lai T, Leinsalu M, Li Y, Liang X, Liu S, Logroscino G, Lotufo PA, Lu Y, Ma J, Mainoo NK, Mensah GA, Merriman TR, Mokdad AH, Moschandreas J, Naghavi M, Naheed A, Nand D, Narayan KM, Nelson EL, Neuhouser ml, Nisar MI, Ohkubo T, Oti SO, Pedroza A, Prabhakaran D, Roy N, Sampson U, Seo H, Sepanlou SG, Shibuya K, Shiri R, Shiue I, Singh GM, Singh JA, Skirbekk V, Stapelberg NJ, Sturua L, Sykes
BL, Tobias M, Tran BX, Trasande L, Toyoshima H, van de Vijver S, Vasankari TJ, Veerman JL, Velasquez-Melendez G, Vlassov VV, Vollset SE, Vos T, Wang C, Wang X, Weiderpass E, Werdecker A, Wright JL, Yang YC, Yatsuya H, Yoon J, Yoon SJ, Zhao Y, Zhou M, Zhu S, Lopez AD, Murray CJ, Gakidou E (2014) Global, regional, and national prevalence of overweight and obesity in children and adults during 1980-2013: a systematic analysis for the Global Burden of Disease Study 2013. Lancet 384:766-781

2. Savino A, Pelliccia P, Chiarelli F, Mohn A (2010) Obesity-related renal injury in childhood. Horm Res Paediatr 73:303-311

3. Jolliffe CJ, Janssen I (2006) Vascular risks and management of obesity in children and adolescents. Vasc Health Risk Manag 2: $171-187$

4. Srinivasan SR, Bao W, Wattigney WA, Berenson GS (1996) Adolescent overweight is associated with adult overweight and related multiple cardiovascular risk factors: the Bogalusa Heart Study. Metabolism 45:235-240

5. Kalupahana NS, Moustaid-Moussa N (2012) The adipose tissue renin-angiotensin system and metabolic disorders: a review of molecular mechanisms. Crit Rev Biochem Mol Biol 47:379-390

6. Sarzani R, Salvi F, Dessi-Fulgheri P, Rappelli A, Dessì-Fulgheri P, Rappelli A (2008) Renin-angiotensin system, natriuretic peptides, obesity, metabolic syndrome, and hypertension: an integrated view in humans. J Hypertens 26:831-843

7. Thethi T, Kamiyama M, Kobori H (2012) The link between the renin-angiotensin-aldosterone system and renal injury in obesity and the metabolic syndrome. Curr Hypertens Rep 14:160-169

8. Frigolet ME, Torres N, Tovar AR (2013) The renin-angiotensin system in adipose tissue and its metabolic consequences during obesity. J Nutr Biochem 24:2003-2015

9. Yasue S, Masuzaki H, Okada S, Ishii T, Kozuka C, Tanaka T, Fujikura J, Ebihara K, Hosoda K, Katsurada A, Ohashi N, Urushihara M, Kobori H, Morimoto N, Kawazoe T, Naitoh M, Okada M, Sakaue H, Suzuki S, Kazuwa N (2010) Adipose tissuespecific regulation of angiotensinogen in obese humans and mice: impact of nutritional status and adipocyte hypertrophy. Am J Hypertens 23:425-431

10. Cooper R, McFarlane-Anderson N, Bennett FI, Wilks R, Puras A, Tewksbury D, Ward R, Forrester T (1997) ACE, angiotensinogen and obesity: a potential pathway leading to hypertension. J Hum Hypertens 11:107-111

11. Gu P, Xu A (2013) Interplay between adipose tissue and blood vessels in obesity and vascular dysfunction. Rev Endocr Metab Disord 14:49-58

12. Okada S, Kozuka C, Masuzaki H, Yasue S, Ishii-Yonemoto T, Tanaka T, Yamamoto Y, Noguchi M, Kusakabe T, Tomita T, Fujikura J, Ebihara K, Hosoda K, Sakaue H, Kobori H, Ham M, Lee YS, Kim JB, Saito Y, Kazuwa N (2010) Adipose tissue-specific dysregulation of angiotensinogen by oxidative stress in obesity. Metabolism 59:1241-1251

13. Kobori H, Nangaku M, Navar LG, Nishiyama A (2007) The intrarenal renin-angiotensin system: from physiology to the pathobiology of hypertension and kidney disease. Pharmacol Rev 59: 251-287

14. Kuroczycka-Saniutycz E, Wasilewska A, Sulik A, Milewski R (2013) Urinary angiotensinogen as a marker of intrarenal angiotensin II activity in adolescents with primary hypertension. Pediatr Nephrol 28:1113-1119

15. Saito T, Urushihara M, Kotani Y, Kagami S, Kobori H (2009) Increased urinary angiotensinogen is precedent to increased urinary albumin in patients with type 1 diabetes. Am J Med Sci 338:478480

16. Urushihara M, Nagai T, Kinoshita Y, Nishiyama S, Suga K, Ozaki N, Jamba A, Kondo S, Kobori H, Kagami S (2015) Changes in urinary angiotensinogen posttreatment in pediatric IgA nephropathy patients. Pediatr Nephrol 30:975-982 
17. Barton M, Carmona R, Morawietz H, D'Uscio LV, Goettsch W, Hillen H, Haudenschild CC, Krieger JE, Munter K, Lattmann T, Luscher TF, Shaw S (2000) Obesity is associated with tissuespecific activation of renal angiotensin-converting enzyme in vivo: evidence for a regulatory role of endothelin. Hypertension 35:329-336

18. Sato E, Mori T, Satoh M, Fujiwara M, Nakamichi Y, Oba I, Ogawa S, Kinouchi Y, Sato H, Ito S, Hida W (2016) Urinary angiotensinogen excretion is associated with blood pressure in obese young adults. Clin Exp Hypertens 38:203-208

19. The NS, Richardson AS, Gordon-Larsen P (2013) Timing and duration of obesity in relation to diabetes: findings from an ethnically diverse, nationally representative sample. Diabetes Care 36:865872

20. Abdullah A, Amin FA, Hanum F, Stoelwinder J, Tanamas S, Wolf R, Wong E, Peeters A (2016) Estimating the risk of type-2 diabetes using obese-years in a contemporary population of the Framingham Study. Glob Health Action 9:30421

21. Kang AK, Miller JA (2002) Effects of gender on the reninangiotensin system, blood pressure, and renal function. Curr Hypertens Rep 4:143-151

22. Remuzzi G, Perico N, Macia M, Ruggenenti P (2005) The role of renin-angiotensin-aldosterone system in the progression of chronic kidney disease. Kidney Int Suppl S57-S65

23. Sachse A, Wolf G (2007) Angiotensin II-induced reactive oxygen species and the kidney. J Am Soc Nephrol 18:2439-2446

24. Patinha D, Afonso J, Sousa T, Morato M, Albino-Teixeira A (2014) Diabetes-induced increase of renal medullary hydrogen peroxide and urinary angiotensinogen is similar in normotensive and hypertensive rats. Life Sci 108:71-79

25. Sousa T, Oliveira S, Afonso J, Morato M, Patinha D, Fraga S, Carvalho F, Albino-Teixeira A (2012) Role of $\mathrm{H}(2) \mathrm{O}(2)$ in hypertension, renin-angiotensin system activation and renal medullary disfunction caused by angiotensin II. Br J Pharmacol 166:23862401

26. Brezniceanu M-L, Liu F, Wei C-C, Tran S, Sachetelli S, Zhang S-L, Guo D-F, Filep JG, Ingelfinger JR, Chan JSD (2007) Catalase overexpression attenuates angiotensinogen expression and apoptosis in diabetic mice. Kidney Int 71:912-923

27. Larsen PS, Kamper-Jorgensen M, Adamson A, Barros H, Bonde JP, Brescianini S, Brophy S, Casas M, Charles M-AA, Devereux G, Eggesbo M, Fantini MP, Frey U, Gehring U, Grazuleviciene R, Henriksen TB, Hertz-Picciotto I, Heude B, Hryhorczuk DO, Inskip H, Jaddoe VWV, Lawlor DA, Ludvigsson J, Kelleher C, Kiess W, Koletzko B, Kuehni CE, Kull I, Kyhl HB, Magnus P, Momas I, Murray D, Pekkanen J, Polanska K, Porta D, Poulsen G, Richiardi L, Roeleveld N, Skovgaard AM, Sram RJ, StrandbergLarsen K, Thijs C, Van Eijsden M, Wright J, Vrijheid M, Andersen A-MNM, Kamper-Jørgensen M, Adamson A, Barros H, Bonde JP, Brescianini S, Brophy S, Casas M, Charles M-AA, Devereux G, Eggesbø M, Fantini MP, Frey U, Gehring U, Grazuleviciene R, Henriksen TB, Hertz-Picciotto I, Heude B, Hryhorczuk DO, Inskip H, Jaddoe VWV, Lawlor DA, Ludvigsson J, Kelleher C, Kiess W, Koletzko B, Kuehni CE, Kull I, Kyhl HB, Magnus P, Momas I, Murray D, Pekkanen J, Polanska K, Porta D, Poulsen G, Richiardi L, Roeleveld N, Skovgaard AM, Sram RJ, StrandbergLarsen K, Thijs C, Van Eijsden M, Wright J, Vrijheid M, Andersen A-MNM (2013) Pregnancy and birth cohort resources in europe: a large opportunity for aetiological child health research. Paediatr Perinat Epidemiol 27:393-414

28. Correia-Costa L, Afonso AC, Schaefer F, Guimarães JT, Bustorff M, Guerra A, Barros H, Azevedo A (2015) Decreased renal function in overweight and obese prepubertal children. Pediatr Res 78: 436-444

29. Duzova A, Yalçinkaya F, Baskin E, Bakkaloglu A, Soylemezoglu O (2013) Prevalence of hypertension and decreased glomerular filtration rate in obese children: results of a population-based field study. Nephrol Dial Transplant 28(Suppl 4):v166-171

30. Kramer MS, Platt RW, Wen SW, Joseph KS, Allen A, Abrahamowicz M, Blondel B, Breart G, Bréart G, Breart G (2001) A new and improved population-based Canadian reference for birth weight for gestational age. Pediatrics 108:E35

31. Durão C, Severo M, Oliveira A, Moreira P, Guerra A, Barros H, Lopes C, Durao C, Severo M, Oliveira A, Moreira P, Guerra A, Barros H, Lopes C (2014) Evaluating the effect of energy-dense foods consumption on preschool children's body mass index: a prospective analysis from 2 to 4 years of age. Eur J Nutr 54:835843

32. de Onis M, Onyango AW, Borghi E, Siyam A, Nishida C, Siekmann J (2007) Development of a WHO growth reference for school-aged children and adolescents. Bull World Health Organ 85: 660-667

33. de Onis M, Lobstein T (2010) Defining obesity risk status in the general childhood population: which cut-offs should we use? Int J Pediatr Obes 5:458-460

34. Wuhl E, Witte K, Soergel M, Mehls O, Schaefer F (2002) Distribution of 24-h ambulatory blood pressure in children: normalized reference values and role of body dimensions. J Hypertens 20: 1995-2007

35. Zappitelli M, Parvex P, Joseph L, Paradis G, Grey V, Lau S, Bell L (2006) Derivation and validation of cystatin C-based prediction equations for GFR in children. Am J Kidney Dis 48:221-230

36. Correia-Costa L, Morato M, Sousa T, Cosme D, Guimarães JT, Guerra A, Schaefer F, Afonso AC, Azevedo A, Albino-Teixeira A (2016) Urinary fibrogenic cytokines ET- 1 and TGF- $\beta 1$ are associated with urinary angiotensinogen levels in obese children. Pediatr Nephrol 31:455-464

37. Correia-Costa L, Sousa T, Morato M, Cosme D, Afonso J, Areias JC, Schaefer F, Guerra A, Caldas Afonso A, Azevedo A, AlbinoTeixeira A (2016) Oxidative stress and nitric oxide are increased in obese children and correlate with cardiometabolic risk and renal function. Br J Nutr 116:805-815

38. Mao YN, Liu W, Li YG, Jia GC, Zhang Z, Guan YJ, Zhou XF, Liu YF (2012) Urinary angiotensinogen levels in relation to renal involvement of Henoch-Schonlein purpura in children. Nephrology (Carlton) 17:53-57

39. Taranta-Janusz K, Wasilewska A, Debek W, Filonowicz R, Michaluk-Skutnik J, Debek W, Fiłonowicz R, Michaluk-Skutnik J (2013) Urinary angiotensinogen as a novel marker of obstructive nephropathy in children. Acta Paediatr 102:e429-433

40. Nishizaki N, Hirano D, Nishizaki Y, Fujinaga S, Nagata S, Ohtomo Y, Kaneko K, Shimizu T (2014) Increased urinary angiotensinogen is an effective marker of chronic renal impairment in very low birth weight children. Clin Exp Nephrol 18:642-648

41. Luo H, Wang X, Chen C, Wang J, Zou X, Li C, Xu Z, Yang X, Shi W, Zeng C (2015) Oxidative stress causes imbalance of renal renin angiotensin system (RAS) components and hypertension in obese Zucker rats. J Am Heart Assoc 4:102-110

42. Umemura S, Nyui N, Tamura K, Hibi K, Yamaguchi S, Nakamaru M, Ishigami T, Yabana M, Kihara M, Inoue S, Ishii M (1997) Plasma angiotensinogen concentrations in obese patients. Am J Hypertens 10:629-633

43. Van Harmelen V, Ariapart P, Hoffstedt J, Lundkvist I, Bringman S, Arner P (2000) Increased adipose angiotensinogen gene expression in human obesity. Obes Res 8:337-341

44. Engeli S, Böhnke J, Gorzelniak K, Janke J, Schling P, Bader M, Luft FC, Sharma AM (2005) Weight loss and the renin-angiotensinaldosterone system. Hypertension 45:356-362

45. Yanes LL, Sartori-Valinotti JC, Reckelhoff JF (2008) Sex steroids and renal disease: lessons from animal studies. Hypertension 51: 976-981 
46. Gluhovschi G, Gluhovschi A, Anastasiu D, Petrica L, Gluhovschi C, Velciov S (2012) Chronic kidney disease and the involvement of estrogen hormones in its pathogenesis and progression. Rom J Intern Med 50:135-144

47. Klein KO, Baron J, Colli MJ, McDonnell DP, Cutler GB (1994) Estrogen levels in childhood determined by an ultrasensitive recombinant cell bioassay. J Clin Invest 94:2475-2480

48. Courant F, Aksglaede L, Antignac J-PP, Monteau F, Sorensen K, Andersson A-MM, Skakkebaek NE, Juul A, Le Bizec B (2010) Assessment of circulating sex steroid levels in prepubertal and pubertal boys and girls by a novel ultrasensitive gas chromatography-tandem mass spectrometry method. J Clin Endocrinol Metab 95:82-92

49. Burt Solorzano CM, McCartney CR (2010) Obesity and the pubertal transition in girls and boys. Reproduction 140:399-410

50. Correia-Costa L, Cosme D, Nogueira-Silva L, Morato M, Sousa T, Moura C, Mota C, Guerra A, Albino-Teixeira A, Areias JC, Schaefer F, Lopes C, Afonso AC, Azevedo A (2016) Gender and obesity modify the impact of salt intake on blood pressure in children. Pediatr Nephrol 31:279-288 